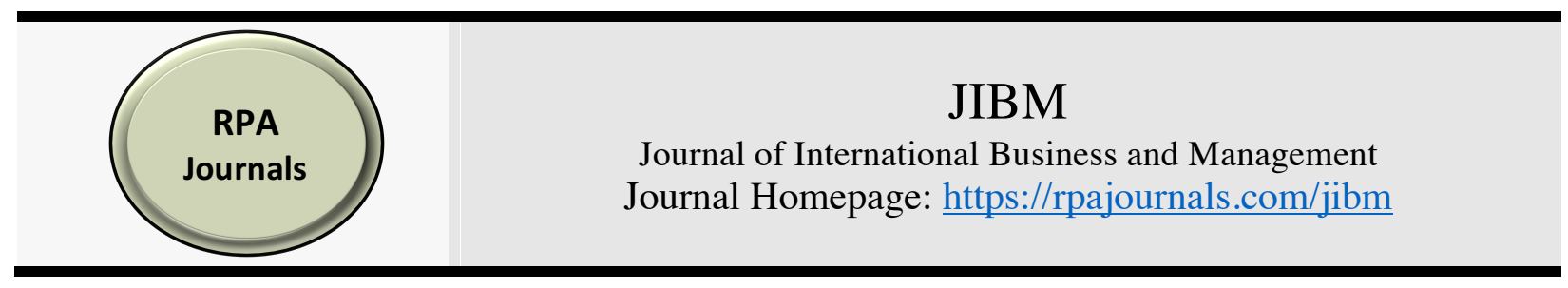

\title{
Understanding the Importance and Practices of Operational Risk Management in Ghanaian Banks
}

\author{
Maxwell Dela Yao Gakpo" \\ Aaron Issa Anafure \\ John Kofi Mensah ${ }^{3}$ \\ University College of Management Studies, Accra, Ghana" \\ Quality Life Assurance Company Limited, Accra, Ghana ${ }^{2}$ \\ Agricultural Development Bank, Accra, Ghana
}

\begin{abstract}
This quantitative study examines the importance and practices of operational risk management in Ghanaian banks. The objective of this paper is to investigate the practitioner's understanding of the difference (if any) between importance and practices of operational risk management programs in Ghanaian banks using a survey research design. The survey instrument, used in collecting data from 170 respondents, was duly validated. The results confirmed that there exists a high level of ORM awareness among the respondents. The banks deploy different risk management solutions to control and mitigate operational risk. The study also concluded that there was a clear difference between perceive ORM importance and ORM practices. This meant that there exists a gap between ORM awareness and ORM program practices. The lack of effective implementation of ORM programs are likely to cause an operational risk contagion among banks with very catastrophic impact on the whole financial sector. The study therefore, recommends that bank mangers commensurate ORM awareness creation with practical implementation of ORM programs and policies in their banks to mitigate operational risk hazards.
\end{abstract}

Keywords: Risk hazards, Operational risk management, ORM Importance, ORM Practices.

*Corresponding author: Maxwell Dela Yao Gakpo; Email: delayaogakpo@gmail.com

DOI: https://doi.org/10.37227/JIBM-2020-04-124

\section{Introduction}

Dermine (2013) posited that, the performance of the banking industry is an indicative of a sound and robust economy. The banking sector therefore mirrors the performance of any economy. Over the past 12 years, from 2008 to 2020, financial institutions particularly, banks, have suffered catastrophic operational risk losses. The lack of effective operational risk management (ORM) practices and excessive risk appetite among bankers were some reasons for the merging banking crisis across the globe (Kashian \& Drago, 2017; Tella, Suraya, Bonsu \& Anani-Bossman, 2020). During the 2008 global banking crisis, stakeholders charged banks to implement effective ORM frameworks aimed at controlling inherent operational risk hazards and external fraud events (Kirkpatrick, 2009). 
Subsequently, banks re-enforced their internal controls and introduced ORM programs. However, the mitigation efforts by banks failed to yield the necessary impact. Rather, operational risk losses increased as a result of operational risk management (ORM) failures (Kashian \& Drago, 2017).

ORM failures in banks received a worldwide attention leading to the review of major international banking reforms (Cope, Mignola, Antonini \& Ugoccioni, 2009; Cruz, Peters \& Shevchenko, 2015). While some studies criticized the absence of ORM program awareness as responsible for the devastating effect of ORM failure in banks (Goldstein et al., 2011; Kessler, 2007); other studies also censured the lack of effective ORM practices in banks (BCBS, 2012; Bryce, Cheevers \& Webb, 2013). The perspectives and differences in opinion about the causes of bank failures, financial crisis and risk contagion will go on for decades until investigative researches are conducted to separate the facts from fictions. Therefore, this study sought to examine the basis of the problem of compliance to Basel II's operational risk management framework. The basis of the framework is a bank's commitment to an ORM program success and secondly, the implementation of same to control and mitigate operational risk hazards.

A recent survey by Ghana Association of Bankers (GAB) revealed that $60 \%$ of 1,021 respondents claimed that risk management was the greatest challenge the Ghanaian banking sector was faced with. Like local banks, internationally active banks (IABs) in Ghana, also experienced ORM failures associated with non-performing loans, corporate scandals, business disruption and transaction entry errors (Amuakwa-Mensah \& Boakye-Adjei, 2015; Banahene, 2018). Researchers have identified risk, systems failures, poor corporate governance and lack of compliance to regulation, poor internal controls practices, internet fraud and hacking of customer account and fraudulent financial dealings as OR hazards affecting banks (Banahene, 2018; Boahene, Dasah \& Agyei, 2012). Poor corporate governance and financial misappropriation resulted into the closure of two major banks; Bank for Housing and Construction and Ghana Cooperative Bank (see table 1). As at 2019 , more than 50 financing institutions, and more than 10 banks collapsed as result of nonperforming loans, financial insolvency, poor investment practices and lack of regulatory compliance (Banahene, 2018; Tella, Suraya, Bonsu \& Anani-Bossman, 2020).

Table 1 ORM failures in Ghanaian Banks

\begin{tabular}{|c|c|c|c|c|c|}
\hline Company & Date & Status & $\begin{array}{l}\text { Assets base (\$ } \\
\mathrm{m})\end{array}$ & $\begin{array}{c}\text { Creditor } \\
\text { base }(\$ \mathrm{~m})\end{array}$ & $\begin{array}{c}\text { Staff } \\
\text { Count }\end{array}$ \\
\hline Bank for Housing \& Construction & 2000 & Official liquidation & 12 & 16 & 1000 \\
\hline Ghana Cooperative Bank & 2000 & Official liquidation & 2 & 7 & 400 \\
\hline 30 Microfinance Institutions & 2013 & Receivership & - & & Over 2,300 \\
\hline 2 Commercial Banks & 2018 & Insolvency & - & & Over 1,356 \\
\hline 5 Commercial Bank & 2018 & Revocation/Takeover & $50 \mathrm{~b}$ & & Over 18,000 \\
\hline 25 Savings and Loan Companies & 2019 & Insolvency & - & & Over 37,500 \\
\hline
\end{tabular}

Source: Adapted from BoG (2020)

The significance of this study is underpinned by the future research suggestion by Pitinanondha (2008), and ORM validation requirement in other sectors and countries by Akpolat and Pitinanondha (2009). Also, Basel II under the Basel Committee on Banking Supervision, enjoined internationally active banks and financial institutions to ensure proper and effective ORM Program implementation across the global financial landscape. The main objective of this paper was to investigate the difference (if any) between the importance and practices of operational risk management in Ghanaian banks. ORM Importance scale refer to ORM program awareness creation among practitioners, while ORM Practice scale focused on the actual implementation of ORM programs and guidelines.

\section{Literature Review}

This session captures extant literature on operational risk management (ORM) Importance (ORM program awareness creation) and ORM Practices (actual implementation of ORM programs) in the banking sector. The literature review captures the different perspectives operational risk management practices; and the technology solutions deployed to ensure effective implementation of operational 
risk management programs. The study also provided a background to perceived ORM importance in banking.

\section{Operational Risk Management in Banking}

Historically, organizations formulated and executed their operational risk management (ORM) programs and strategies purposively to minimize the incidence of loss and severity of impact, on their operations (Hull, 2012). This tradition practice cuts across many sectors, industries and organizations. ORM phenomenon is now a topical subject in banking and financial services sector due to the negative impact of operational risk on global banking operations in recent times (Bryce, Cheevers \& Webb, 2013). Doerig (2003, p. 85) described operational risk management (ORM) as a "comprehensive management process that involves the creation of appropriate risk management environment, involvement of employees at all levels, development and dissemination of risk management plans, policies, and strategies, alignment of responsibilities to leadership roles, implementing qualitative and financial measures, providing risk appropriate training and risk-based performance assessment, and establishing adequate internal controls and management reporting systems".

The explanation of Doerig (2003) and Hull (2012), makes the development and implementation of operational risk management programs and strategic alignment to organizational goals, a serious leadership and management concern for banks. The Basel Committee on Banking Supervision in response to the growing banking crisis across the globe, enjoined all internationally active banks to develop, implement and commit to an effective ORM framework (BCBS, 2012). How important is the development and implementation of an ORM program for Ghanaian banks?

\section{Operational Risk Management Importance}

The importance of operational risk management programs and awareness creation in the banking sector cannot be over-emphasized. Studies by Namazian and Eslami, (2011) and Pitinanondha (2008) underpinned the relevance of ORM Importance as a critical measure to control and mitigate operational risk hazards in banking operations. The importance of operational risk management program awareness in the banking sector evolved from different perspectives and frameworks. These frameworks include but not limited to; economic management (Goldstein, et al., 2011), risk-based regulation and supervision (Aebi, Sabato \& Schmid, 2012), enterprise risk management (Bromiley, McShane, Nair \& Rustambekov, 2014), quality and operations management (Akpolat \& Pitinanondha, 2009), systemic models (Kessler, 2007), qualitative and quantitative management (Ana-Cornelia, 2012; Hull, 2012), corporate risk governance (Dermine, 2013), COSO framework (Tahir, 2020) and Basel accords (BCBS, 2012).

\section{Operational Risk Management Practices}

Practicing effective operational risk management models to reduce operational risk loss incidents and its severity on banking operations is critical to the survival of the financial sector as whole. In this respect, researchers and practitioners have considered operational risk management as a comprehensive phenomenon, studied and implemented from different perspectives (Chapman, 2012; Hull, 2012). The study by Ana-Cornelia (2012) confirmed the implementation diversity of ORM and posited that ORM underwent different evolutions, managing perspectives, solutions, and management strategies. The study by Ana-Cornelia (2012) also presented a five-stage operational risk management programs' implementation for commercial banks. The operational risk management practice guidelines are applicable to banks and non-bank financial institutions seeking to reduce operational risk loss and severity, and its consequential effect on profitability. These practical implementation guidelines include:

1. Traditional basic line: At this stage, OR governance is by the internal control policies. Also the responsibility is taken by the individual line managers and there are no management formal frameworks. 
2. The awareness period: At this stage, management key role is to support the evaluation process of the company. The evaluation starts with a definition for the OR politics and the development of the common instruments for protection.

3. The monitoring period: OR effects on the business are analyzed and OR program is introduced.

4. The quantification period: This stage involves the existing of the analytical instruments based on actual data, and determining the financial impact on the entire organization.

5. The Integration period: This stage embraces different business comparisons, qualitative versus quantitative management processes.

For an effective ORM program implementation in banking, Pitinanondha (2008) also suggested four basic approaches for practitioners. These include:

1. The banks should establish internal and external ORM content, ORM evaluation criteria and defined structures for ORM analysis and priorities.

2. The banks should empower employees across the entire bank to identify and report any OR hazards for early identification and control. Communication and training is recommended tool for employee empowerment.

3. The banks should incorporate ORM into the overall internal controls systems. The controls should help in estimating expected OR levels and analysis, and determination of OR probability and consequences of occurrence.

4. The banks should deploy ORMS solutions to identify and assess ORM options and mitigation strategies and plans.

Basel II framework by Basel Committee on Banking Supervision (BCBS, 2012) also recommended a seven-step practical approach for stakeholders. These practical ORM guidelines from Basel II, second of the Basel Accords, was designed to guide stakeholders particularly, practitioners to control and mitigate the effect of operational risk on banking operations. The guidelines were to ensure an effective development and implementation of ORM programs, policies and strategies that are aligned with general banking operations and business activities at all levels, departments and business lines. Basel II's seven-step practice-base approaches are as follows:

1. Commit to the success of an ORM programs.

2. Develop the bank's mission, vision and objectives for effective ORM performance.

3. Define ORM policy and strategic alignments for an effective ORM implementation.

4. Drive and communicate ORM across the entire bank.

5. Provide adequate resources and support for ORM programs and activities.

6. Regularly review ORM performances individuals, departments and business units.

7. Establish appropriate levels of recognition, reward, approval and sanction for ORM performance appraisals

\section{Operational Risk Management Solutions}

Some studies have revealed that banks were gradually integrating two or more technology solutions into the overall corporate risk governance of their banks as opposed to the use of a generic or standalone risk management solutions (Dermine, 2013; Cruz, et al., 2015). Integrated ORM solutions for banks have increased in recent times (Dermine, 2013). These ORM technology solutions were designed to support banks achieve effective ORM compliance and effectively control and mitigate operational and other types of risk. These off-the-shell technology solutions include but not limited to: Basel 3 Technology Solutions, OpRisk Solutions, RiskTech100, Global Risk IT Expenditure, Enterprise GRC Systems, and Enterprise Fraud Management Solutions for Financial Services, and ORM Solutions for Financial Services (BCBS, 2012; Chartis Report, 2013, Hull, 2012). 


\section{Methodology}

The study used a survey method in the collection data from 170 respondents covering Operational Risk Managers, Head of Risk Department, Risk Managers, Risk and Legal Department, Risk and Audit Unit, Risk and Assurance Unit, and Credit risk managers across 30 banks in Accra. A mailed questionnaire considered to be quicker and economical in survey designs was deployed in the collection of data for the analysis. The descriptive statistical analysis was performed using chart, arithmetic mean and standard deviation. The inferential statistical analysis was performed using ttest analysis.

\section{Results and Discussions}

The descriptive analysis sought to examine the respondents' knowledge or perception of ORM awareness (Importance) in their banks beginning with years of working experience in the risk management position in their respective banks. The responses were; less than five years $160(94 \%)$ and five or more years $10(6 \%)$. All 170 respondents were quizzed on whether or not there exists a formal ORM program in their banks. Their responses were: Yes, formal ORM program exists, 168 (99\%), and No ORM program $2(1 \%)$. This indicated high level of ORM awareness. These respondents further indicated that their banks deploy a single ORM program solution $76(45 \%)$, multiple ORM solutions $92(54 \%)$ to manage their OR. The respondents were familiar with these solutions; Basel accords 70 (23\%), Scorecard 30 (10\%), COSO 15 (5\%), ISO 3100059 (19\%), and Internal Controls $129(43 \%)$ (see figure 1).

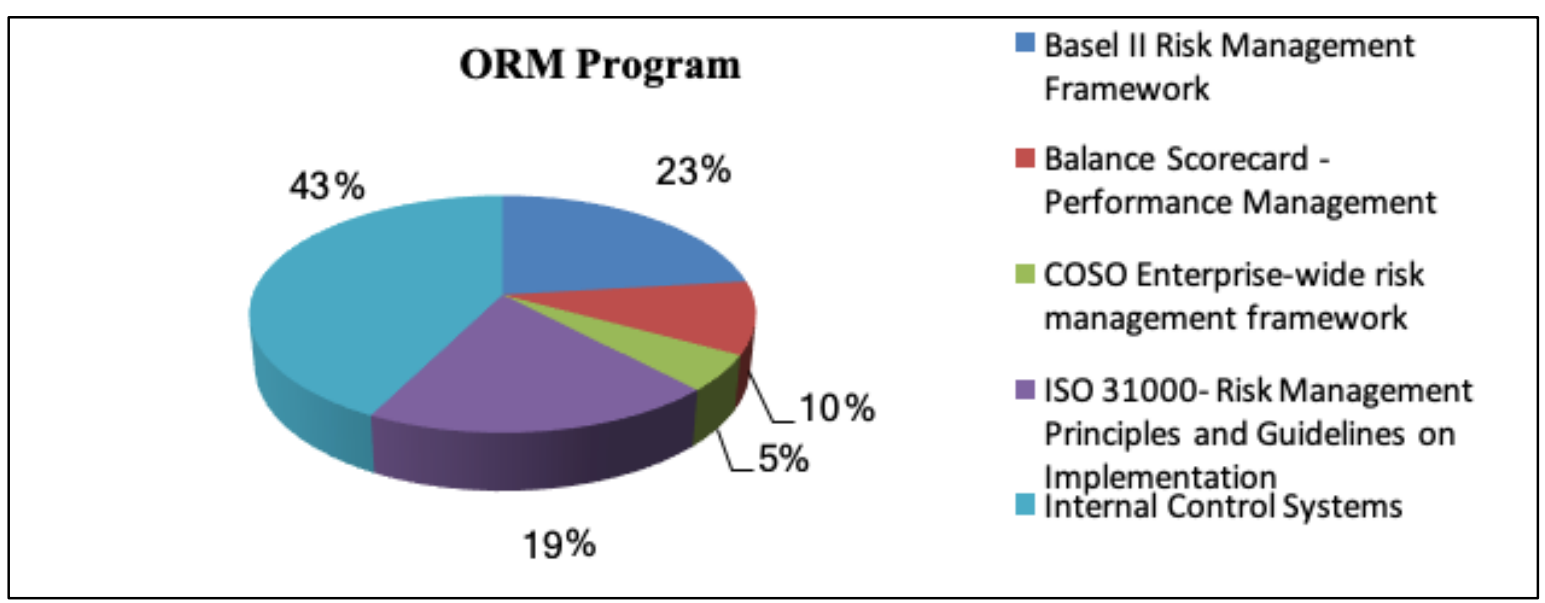

Figure 1. Exposure to ORM Solutions

The result of the main hypothesis, sought to investigate the difference (if any) between perceived ORM Importance and ORM Practice in Ghanaian banks. In other to investigate the relationship or otherwise of the two means, Practice mean and Importance mean of ORM; a t-test was necessary.

Table 2 presents the values of the Practice mean. The values range from 3.78 to 3.48. Risk governance scale recorded the highest mean value of 3.78 with a standard deviation value of 1.12. This is indicative of the pivotal role played by "risk governance" in the implementation of operational risk management programs and policies. From the table, the overall average mean value for operational risk management scale stood at 3.64. On a 5-point Likert scale, the average mean value of 3.64 indicates a low perception (Norman, 2010). This meant that actual ORM program practice by respondents is low. It perceived by the respondents that actual ORM program implementation to curb operational risk hazards have not been commensurate to ORM program hype and awareness in Ghanaian Banks. 
Table 2: Mean and Standard Deviation for ORMS Factors (Practice Scale)

\begin{tabular}{llll}
\hline Factor & Mean & SD & Ranking \\
\hline Risk Governance (RG) & 3.78 & 1.12 & 1 \\
Risk Management Policy (RMP) & 3.71 & 1.16 & 3 \\
Risk Management Planning (RMPg) & 3.66 & 1.08 & 5 \\
Risk Management Implementation (RMI) & 3.69 & 1.12 & 4 \\
Customized Risk Management Process (CRMP) & 3.48 & 1.14 & 8 \\
Risk-based Performance Appraisal (RbPA) & 3.57 & 1.09 & 6 \\
Risk Management Culture (RMC) & 3.72 & 1.05 & 2 \\
Risk Management Training (RMT) & 3.54 & 1.105 & 7 \\
\hline Overall Mean (ORM) Practice Scale & 3.64 & 1.11 & \\
\hline
\end{tabular}

The mean of perceived ORM Importance (see table 3) ranged from 4.60 to 4.53 . From the table, the factor "risk management implementation" obtained the lowest mean of 4.53 with a standard deviation of 0.87 . In contrast, the factor "risk management policy" was perceived to be the most important scale with the highest mean value of 4.60 and a standard deviation of 0.80 . Therefore, risk management policy was ranked the most important factor. The rankings also showed small margins in the values of the means and standard deviations of the ORM Importance factors. The results proved that respondents placed high premium on ORM Importance (average mean 4.56) than ORM Practice.

High perception of ORM Importance and low perception of ORM Practice indicates a difference in the two scales shown by the differences in the two means and corresponding standard deviations. The descriptive result shows that ORM Importance in terms of risk management policy awareness was more regarded in the respondents banks that ORM Practice which is indicative of ORM program implementation.

Table 3 Mean and Standard Deviation for the dimensions of ORM (Importance Scale)

\begin{tabular}{llll}
\hline Factor & Mean & SD & Ranking \\
\hline Risk Governance & 4.56 & 0.81 & 2 \\
Risk Management Policy & 4.60 & 0.80 & 1 \\
Risk Management Planning & 4.53 & 0.87 & 5 \\
Risk Management Implementation & 4.55 & 0.87 & 3 \\
Customized Risk Management Process & 4.54 & 0.88 & 4 \\
Risk Management Training & 4.54 & 0.92 & 4 \\
Risk-based Performance Appraisal & 4.56 & 0.83 & 2 \\
Risk Management Culture & 4.56 & 0.85 & 2 \\
\hline Overall Mean (ORM) Importance & 4.56 & 0.85 & \\
\hline
\end{tabular}

The paired sample statistics for ORM practice scale (PS) and ORM importance scale (IS), and the means and standard deviations for all the factors were compared (see table 4). The standard error of the mean (SEM) showed relatively low values for the ORM factors. The t-test statistical analysis, showed that there was a significant difference between the perceived ORM Importance factors when compared ORM practice factors. It was significant at .000 . The results clearly meant that there was increased ORM awareness however, this perceived importance did not translate into real ORM practices in the banks. Therefore, the hypothesis was supported. The t-test result confirms the result obtained in the descriptive statistic. The results confirmed the study by (Pitinanondha, 2008) that perceive ORM importance among practitioners as compared to lower perception on ORM practices. 


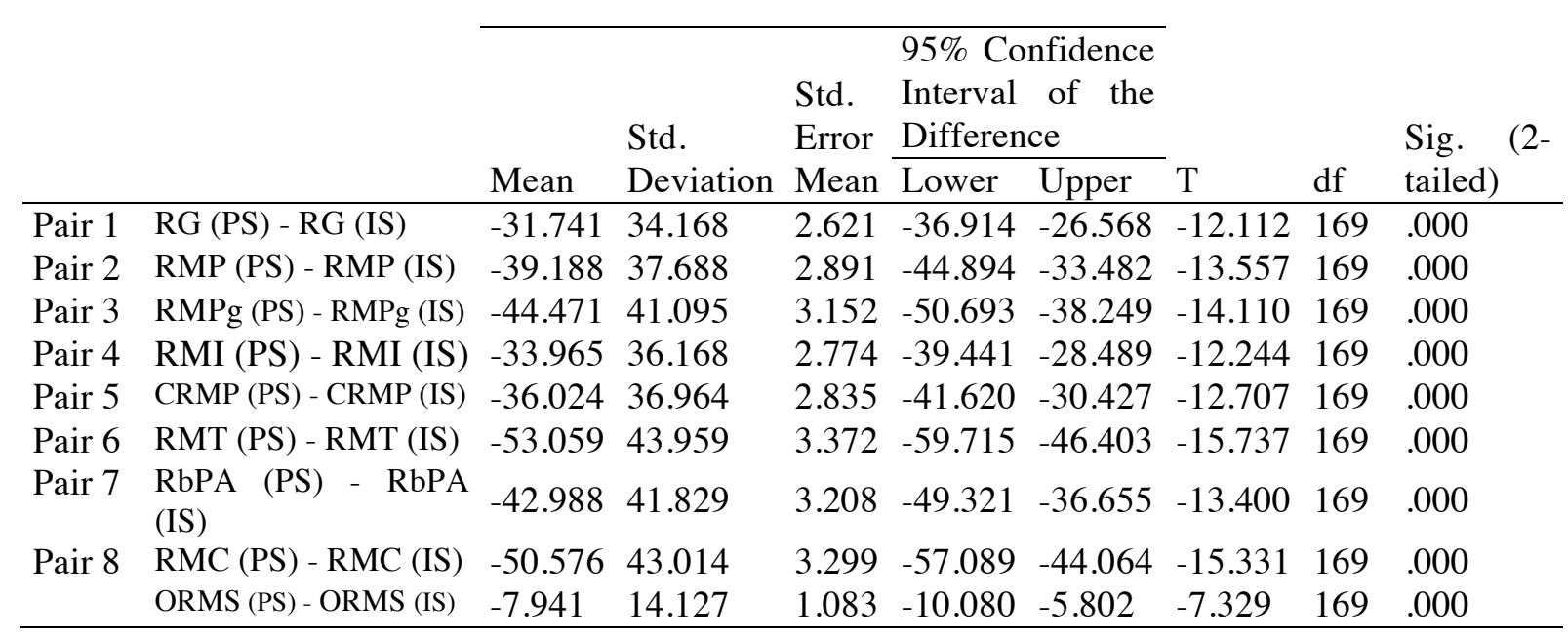

\section{Conclusions}

The study concluded that the respondents were well informed about ORM programs and activities in their banks. Through workshops and seminars, the respondents were engaged on the importance of ORM programs implementation. The study further concluded that the respondents use either a single/generic or an integrated ORM solution to control and mitigate OR. The respondents were also exposed to some basic ORM solutions necessary for effective ORM practices in their banks. Examples of these includes OPTIAL, COSO and Enterprise Risk Solutions.

The t-test analysis reveals that there was a clear difference between perceived ORM Importance and real ORM practices in Ghanaian banks. Even though there was enough evidence of perceived increased in ORM programs, the actual implementation was however lacking. Therefore, the result supports the hypothesis that, there was a significant difference between ORM importance and ORM practices in Ghanaian banks. This confirms the theoretical proposition by Aebi et al., 2012, and Akpolat et al. 2009.

\section{Recommendations}

First, the study recommends the promotion of ORM practices through regular need assessment, ORM skill development and appropriate training for practitioners. The yearly mandatory staff appraisal and promotions should take recognizance of the practitioners ORM skill development and training participation. Secondly, the respondent banks should develop a strategic implementation plan that is consistent and aligned with their ORM programs. ORM programs should follow a consistent strategy and policy alignment for an effective implementation. Hence, ORM programs should be integrated into the entire strategic risk management practices across the bank. This will help strengthen the internal controls and mitigate people risk, system risk and process risk on banking operations. Also, management should police and regularly monitor the entire ORM program implementation process to ensure its success and commitment of all employees. A regular monitoring and policing of the process will enable top management to appraise, evaluate and review the effectiveness of the ORM programs and implementation strategies. Finally, Bank of Ghana should ensure that all internationally active banks in Ghana comply with the Basel II, and adhere to the development and implementation of ORM programs. In order to ensure compliance by individual banks, the regulator, should embed ORM program implementation to its risk-based supervision mandate.

\section{Limitations and Future Directions}

The only limitation of the study was in respect to scope of the study. The study was restricted to only banks in Accra with a functional risk management department. Whereas most banks decentralized risk management function to individual branches; some banks centralized operational risk 
management function at their head office. The later banks consider operational risk management as a top management role. Future research on the subject should explore a much wider scope and coverage, and also use the banks financial statements for a comparative analysis of ORM program awareness creation as against actual ORM program implementation. A benefit analysis of compliance and non-compliance of ORM program implementation will be topical for future researchers.

\section{References}

Aebi, V., Sabato, G., \& Schmid, M. (2012). Risk management, corporate governance, and bank performance in the financial crisis. Journal of Banking \& Finance, 36(12), 3213-3226.

Akpolat, H., \& Pitinanondha, T. (2009). A framework for systematic management of operational risks. Asian Journal on Quality, 10(2), 1-17.

Amuakwa-Mensah, F., \& Boakye-Adjei, A. (2015). Determinants of non-performing loans in Ghana banking industry. International Journal of Computational Economics and Econometrics, 5(1), 35-54.

Ana-Cornelia, O. (2012). The operational risk management. Universitatii Maritime Constanta. Analele, 13(18), 335.

Banahene, K. O. (2018). Ghana banking system failure: the need for restoration of public trust and confidence. International Journal of Business and Social Research, 8(10), $1-5$.

Basel Committee on Banking Supervision. (2012). Principles for the sound management of operational risk. Quarterl reports. June, 1-27.

Boahene, S. H., Dasah, J., \& Agyei, S. K. (2012). Credit risk and profitability of selected banks in Ghana. Research Journal of finance and accounting, 3(7), 6-14.

Bromiley, P., McShane, M., Nair, A., \& Rustambekov, E. (2014). Enterprise risk management: review, critique, and research directions. Forthcoming: Long Range Planning.

Bryce, C., Cheevers, C., \& Webb, R. (2013). Operational risk escalation: an empirical analysis of UK call centres. International Review of Financial Analysis, 30, 298307.

Chapman, R. J. (2012). Operational risk management with simple tools and techniques for enterprise risk management (pp. 267-308).

Chartis, R. (2013). Operational risk management systems for financial services. 2013 Chartis Annual Report.

Cope, E., Mignola, G., Antonini, G., \& Ugoccioni, R. (2009). Challenges and pitfalls in measuring operational risk from loss data. The Journal of Operational Risk, 4, 3-28.

Creswell, J. (2013). Qualitative, quantitative, and mixed methods approaches. In Research design (pp. 1-26).

Cruz, M. G., Peters, G. W., \& Shevchenko, P. V. (2015). Fundamental aspects of operational risk and insurance analytics: A handbook of operational risk. John Wiley \& Sons.

Dermine, J.(2013). Bank corporate governance beyond the global banking crisis. Financial Markets, Institutions \& Instruments, 22(5), 259-281.

Goldstein, J., Chernobai, A., \& Benaroch, M. (2011). An event study analysis of the economic impact of it operational risk and its subcategories. Information Systems Journal, 12, 606-631.

Hull, J. C. (2012). Risk management and financial institutions (Third Edition.). John Wiley \& Sons, Ltd. 
Kashian, R., \& Drago, R. (2017). Minority-owned banks and bank failures after the financial collapse. Economic Notes: Review of Banking, Finance and Monetary Economics, 46(1), 5-36.

Kessler, A. M. (2007). A systemic approach framework for operational risk. -SAFOR.

Kirkpatrick, G. (2009). The corporate governance lessons from the financial crisis. OECD Journal of Financial Market Trends, 34(7), 849-855.

Koomson, A. (2011). Operational risk management and competitive advantage in the banking industry in Ghana. Unplished thesis dissertation.

Namazian, A., \& Eslami, N. (2011). Operational risk management. Australian Journal of Basic Applied Sciences, 5, 3240-3245.

Norman, G. (2010). Likert scales, levels of measurement and the "laws" of statistics. Advance in health sciences education, 15(5), 625-632.

Pitinanondha, T. (2008). Operational risk management (ORM) systems - An Australian study. University of Technology Sydney: Australia.

Tahir, A. P. D. C. M. (2020). The use of the Six Sigma approach in activating the internal control components in accordance with the COSO framework in the banking sector. Tikrit Journal of Administration and Economics Sciences, $16(51$ part 1).

Tella, F., Suraya, A., Bonsu, M. A., \& Anani-Bossman, A. A. (2020). Crisis Communication and Ghana's Financial Sector. Covenant Journal of Communication, 7(1). 